\title{
Evidências ideológicas que mobilizam a educação para o trabalho
}

\author{
Maria Virgínia Borges Amaral \\ Assistente Social, Doutora em Lingüística, \\ Professora da Faculdade de Serviço Social e do \\ Programa de Pós-graduação em Letras e \\ Lingüística da Universidade Federal de Alagoas. \\ E-mails: MVBA@FAPEAL.BR, \\ MVBA@CCSA.UFAL.BR.
}

Resumo: Implicaçōes, com base no campo de conhecimento da Análise do Discurso, da afirmação da existência da ideologia como matriz geradora e reguladora da relação entre o dito e 0 não-dito, o visível e o invisível, o imaginável e o inimaginável no reconhecimento de sua presença na instância do discurso, especificamente na relação entre essa noção e a de memória discursiva, produzindo efeitos ideológicos capazes de mobilizar a educação para o trabalho na sociedade capitalista.

Palavras-chave: discurso; efeitos ideológicos; memória discursiva; trabalho
Abstract: Based on the knowledge area of Discourse Analysis, this paper presents reflections on the statement of the existence of ideology as a generating and regulating matrix in the relations between what is said and unsaid, visible and invisible, imaginable and unimaginable, in the recognition of its presence in discourse, specifically in the relation between this notion and that of discursive memory, producing ideological effects which are, in turn, capable of setting forth work-oriented education in capitalist society.

Keywords: discourse; ideological effects; discursive memory; work 



\section{Introdução}

Há algum tempo, quando me deparei com a teoria da Análise do Discurso, em 1993, percebi que estava diante de grandes desafios no campo do conhecimento. Quando parecia haver concluído uma pesquisa sobre o discurso da formação profissional do assistente social, novos objetos de análise foram se delineando e despertando-me o interesse para continuar a investigação sobre o campo de atuação do Serviço Social. Além disso, os aspectos teórico-metodológicos da Análise do Discurso me fascinavam devido ao instigante debate que se trava nessa área limítrofe entre filosofia, política, história. Acresceu-se à minha formação no Serviço Social e na sociedade capitalista um novo caminho para a interpretação dos discursos que representam e sustentam essa forma de ser da sociedade, suas contradições, seus processos de dominação e, sobretudo, as formas de subsunção do trabalho ao capital. A Análise do Discurso me estimulou a continuar minhas pesquisas acerca do trabalho e das formas encontradas pelos homens para manter o processo de controle e dominação.

Em 1997 comecei a investigação sobre o discurso do empresário, o que considero ser um trabalho significativo nessa minha trajetória de analista do discurso. Essa pesquisa mostrou-me a possibilidade de identificar o jogo de evidências ideológicas que um discurso é capaz de produzir.

Durante todo esse tempo de pesquisa, procurei sempre retomar algumas reflexões sobre o discurso do empresário que ficaram a depender de maior envergadura teórica. Propus-me rever textos que tomei como material empírico da investigação num determinado momento dos meus estudos e interpretar o funcionamento discursivo que conduz à produção dos efeitos de sentidos, sobretudo as evidências ideológicas, o papel da memória discursiva e os efeitos metafóricos que produzem sentidos e mobilizam práticas. Hoje, acrescentaram-se aos meus estudos mais algumas reflexões acerca da Análise do Discurso e proponho-me continuar investigando, não a concluir, visto 
1 "A consciência jamais pode ser outra coisa do que o ser consciente, $\mathrm{o}$ ser dos homens éo processo de vida real".(MARX, 1986, p. 37). que me parece impossível completar o incompletável, isto porque compreendo que a leitura, a interpretação, é circunstancial, obtendo-se sempre um relativo acabamento em textos que resultam do processo de investigação.

Aqui reforço a compreensão de que discurso é um todo concreto, resultado de processos sócio-históricos, e "o concreto é concreto por ser a síntese de múltiplas determinações, logo a unidade da diversidade" (MARX, 1983, p.218). O discurso como concreção do pensamento, de idéias, é também produto da prática social, é determinado pelo ser social. Assim como se refere Marx à determinação da consciência: "a consciência, portanto, é desde o início um produto social, e continuará sendo enquanto existirem homens" (1986, p. 43) ${ }^{1}$. O discurso, pois, é resultado do processo de abstração da realidade; é objeto pensado, e se apresenta como objeto acabado, entendido como um complexo pelo qual as idéias ganham materialidade.

A discussão sobre as idéias e seu lugar, sua função no processo de produção e reprodução da sociabilidade humana, remete nesse campo de saber dos discursos à discussão sobre ideologia. Tal discussão está longe de ser concluída, porque "o fim da ideologia" (no sentido restrito, o que designa formas ideológicas nas sociedades de classes) estaria associado à superação da sociedade de classes. Só com a transformação radical do modo de produção capitalista se poderiam resolver os conflitos reproduzidos pelos interesses opostos das classes, interesses que estão condicionadas à produção material na estrutura política e social da sociedade capitalista.

Trato a seguir da ideologia, da inserção dessa temática no campo da Análise do Discurso e da relação que se estabelece com a noção de memória discursiva, um conceito que se distancia da noção de "memória" como consciência/inconsciente, para adquirir o sentido de historicidade discursiva.

\section{Sobre a ideologia}

Como sabemos muito bem, o conceito de ideologia é deveras polêmico. Sugere muitas interpretações, mas, 
suponho, todos que o tomam para análise encontram dificuldade em negar a sua pertinência, seja qual for a concepção teórica que o ancore. No nosso campo de conhecimento, o da Análise do Discurso, podemos afirmar seguramente a existência da ideologia como matriz geradora e reguladora da relação entre o dito e o nãodito, o visível e o invisível, o imaginável e o inimaginável. Istvan Mészáros adverte que mesmo os que apregoam a objetividade ou a isenção da ideologia em certas práticas, como é o caso dos estudos lexicográficos que produzem dicionários, podem ser surpreendidos com a função e o poder da ideologia. Diz ele:

[...] a verdade é que em nossas sociedades tudo está "impregnado de ideologia", quer a percebamos, quer não. Além disso, em nossa cultura liberalconservadora o sistema ideológico socialmente estabelecido e dominante funciona de modo a apresentar - ou desvirtuar - suas próprias regras de seletividade, preconceito, discriminação e até distorção sistemática como "normalidade", "objetividade" e "imparcialidade científica" (MÉSZÁROS, 2004, p. 53).

George Lukács compreende ideologia como função social e a define em sentido amplo e em sentido restrito. Num sentido amplo, a ideologia é "um veículo de conscientização e prévia-ideação da prática social dos homens" (LUKÁCS apud VAISMAN, 1989, p. 420). Nesse sentido, ideologia "é acima de tudo aquela forma de elaboração ideal da realidade que serve para tornar a práxis social dos homens consciente e operativa" (idem, p. 418).

Na perspectiva marxista advoga-se que, em qualquer forma de sociabilidade, a ideologia tem sua existência real, "é exterioridade", não é produto de uma atitude teórica (ou científica). A prática social em todas as suas formas de expressão não está isenta de ideologia, sendo, portanto, essa mesma prática social a
${ }^{2}$ Pêcheux (1988) se refere à existência real da ideologia. Veremos adiante a concepção de ideologia nesse autor. 
O representar, o pensar, o intercâmbio espiritual dos homens, aparecem aqui como emanação direta de seu comportamento material [...]. Os homens são os produtores de suas representações, de suas idéias etc., mas os homens reais e ativos, tal como se acham condicionados por um determinado desenvolvimento de suas forças produtivas e pelo intercâmbio que a ele corresponde até chegar as suas formações mais amplas.

A ideologia, pois, procede da prática social e volta a essa mesma prática como "um processo de produção das formas de representação, das idéias e valores que constituem o fundamento operacional de uma prática específica, mobilizando e conferindo um caráter ético e político a essa prática" (AMARAL, 2005, p. 41).

$\mathrm{Na}$ acepção burguesa, a ideologia opera em sentido restrito. Cumpre seu papel específico junto à luta de classes. $E$, embora não seja restrita à luta de classes, é verdade que na sociedade capitalista a ideologia produz "falsa consciência", impulsiona a "forma de consciência estranhada [...] a ilusão necessária requerida pelo sistema capitalista para sobreviver [...] o falso socialmente necessário" (LUKÁCS apud VAISMAN, 1989, p. 405). Ideologia não é sinônimo de falsa consciência; ela pode gerar falsa consciência. E mais, nem toda formulação de falsa consciência é, ou será, decorrente da ação da ideologia.

É sabido que a história da sociedade burguesa está coroada pelas promessas do Iluminismo, que não se concretizaram. Os "positivistas" postularam que o destino inevitável da maioria dos homens é viver dos frutos mais ou menos precários do trabalho cotidiano, e por isso "o grande problema social é melhorar a condição desta maioria sem destruir sua classificação e sem perturbar a economia geral [...]" (COMTE apud MÉSZÁROS, 2004, p. 465). 
Esses ideólogos burgueses presumiram que "novas idéias" poderiam dar um norte à sociedade que vive da exploração do trabalhador, que o pensamento, desligado dos fatos e da prática que lhe servem de base, daria as coordenadas para a "autoconsciência" e libertaria o homem da sua servidão ${ }^{3}$. Foi então, ante tais desafios postos pela sociedade capitalista, que Destutt de Tracy articulou uma "teoria das idéias" - Ideologia - que se propunha a "fundamentar [...] a educação dos indivíduos destinados a se ajustar sem dificuldades à estrutura social consolidada da ordem burguesa" (idem, p.464).

A ideologia, nessa acepção, caracterizou-se como um empreendimento científico. Acreditava-se na capacidade de tal "empreendimento" fazer os indivíduos se conformar aos imperativos estruturais da sociedade. "Novas idéias" se instituíram, descredenciando a idéia de emancipação humana e corroborando o ideal positivista de fortalecimento da sociedade através da imposição educacional, de reformas e ajustes dos sujeitos à sociedade burguesa. Nesse sentido restrito, ideologia tem história e está associada às relações contraditórias do modo de produção capitalista, portanto, à luta de classes.

Michel Pêcheux trata do conceito de ideologia no sentido geral, mas já o especifica em razão do funcionamento na luta de classes. A "Ideologia" no sentido geral é referida por esse autor no singular, e indicada com letra maiúscula, como sendo "A Ideologia em geral". Por outro lado, a ideologia no sentido restrito está no plural; são as formações ideológicas, as ideologias que têm história própria, uma "existência histórica concreta". Nessa tese, Pêcheux (1988) advoga que a Ideologia em geral não poderia coincidir nem com formação ideológica, nem com ideologia dominante, a qual define como "resultado de conjunto, forma histórica concreta resultante das relações de desigualdade-contradição-subordinação noção que caracteriza, numa formação social historicamente dada, 'o todo complexo com dominante' das formações ideológicas que nela funcionam" (idem, p. 151).
${ }^{3}$ Mas "[...] somente é possível efetuar a libertação real no mundo real e através de meios reais[...] não é possível libertar os homens enquanto não estiverem em condições de obter alimentação e bebida, habitação e vestimenta, em qualidade e quantidade adequadas"(MARX, 1986, p. 65). A "libertação", como diz Marx, "é um ato histórico, não um ato do pensamento, é efetivamente por condições históricas, pela [situ]ação da indústria, do comércio, da agricultura, do intercâmbio[...]". 
${ }^{4}$ Vemos aqui que 0 pensamento de Pêcheux sobre ideologia dominante, embora esteja ancorado na leitura marxista de Althusser, se aproxima sobremaneira do pensamento de Marx: "As idéias da classe dominante são, em cada época, as idéias dominantes [...]" (1986, p. 72). Podemos entender assim: a ideologia dominante éa ideologia da classe dominante da época; logo, na sociedade capitalista a dominante é a ideologia da classe burguesa.
As relações de desigualdade-contradiçãosubordinaçãosão, nessa linha de pensamento de Pêcheux, a matriz reguladora da sociedade de classes, a sociedade capitalista, cujo núcleo, sabemos, é formado pelo tripé capital, trabalho assalariado e Estado. A sociedade capitalista é a forma dominante que o capital assume no decorrer dos séculos XVIII, XIX, XX e continua no século XXI. É, pois, uma formação social historicamente dada em que funciona o que Pêcheux chama o "todo complexo com dominante das formações ideológicas", ou interdiscurso (idem, p. 162), no qual a ideologia dominante $e^{4}$ ganha características específicas advindas da ação do capital, o que a distingue da Ideologia em geral, que "não tem história", no sentido de "história das sociedades de classe".

Para Pêcheux, "o todo complexo com dominante" (ou, como entendemos, o complexo de formações ideológicas com uma ideologia dominante), que ele chama de interdiscurso, característico do complexo das formações ideológicas, é também submetido à lei da sociedade de classes (de desigualdade-contradiçãosubordinação); do interdiscurso depende o caráter material do sentido das palavras, que muda conforme a posição sustentada pelo sujeito-falante, o lugar discursivo que ocupa em referência à posição ideológica em que se inscreve. O sentido das palavras não existe nelas mesmas, mas na dependência do todo complexo das formações ideológicas; os sentidos são determinados "pelas posições ideológicas que estão em jogo no processo sócio-histórico" (idem, p. 160).

É a ideologia que fornece as evidências para que todos os sujeitos se identifiquem e se reconheçam como pertencentes à sociedade, como sujeitos-de-direito, juridicamente instituídos, livres e com iguais oportunidades no jogo da desigualdade-contradiçãosubordinação. Para Pêcheux,

o funcionamento da ideologia em geral como interpelação dos indivíduos em sujeitos (e 
especificamente em sujeitos de seu discurso) se realiza através do complexo das formações ideológicas (e, especificamente, através do interdiscurso intricado nesse complexo) e fornece "a cada sujeito sua realidade", enquanto sistema de evidências e de significações percebidas - aceitas - experimentadas." (idem, p. 162).

É assim que a ideologia se constitui em tema conceitual no corpo teórico da Análise do Discurso. Por isso, devido à complexidade desse tema, a discussão acerca da ideologia não poderá ser excluída do debate da teoria materialista dos processos discursivos.

\section{Sobre memória discursiva e outros dizeres}

A memória discursiva é a existência histórica do enunciado relativo às expressões concretas da ideologia em funcionamento. Mais conceitualmente, a memória discursiva é concernente ao interdiscurso, ao préconstruído, aos discursos-transversos (PÊCHEUX, 1988). A memória discursiva é constituída do que Pêcheux denominou de dois tipos de esquecimentos (idem, 1988): o esquecimento 1 , um sistema da esfera da ideologia, e o esquecimento 2, da esfera do enunciado. Esses esquecimentos produzem no sujeito a ilusão de que o dizer é novo, que é da sua escolha, que é do seu domínio. Produzem um efeito de ocultação no processo de enunciação, colocando fronteiras entre o que é selecionado e o que é rejeitado. Esse processo de seleção e rejeição se dá no interior de uma formação discursiva, "aquilo que, numa formação ideológica dada, isto é, a partir de uma posição dada numa conjuntura dada, determinada pelo estado da luta de classe, determina o que pode e deve ser dito (articulado sob a forma de uma arenga, de um sermão, de um panfleto, de uma exposição, de um programa etc.)" (PECHEUX, 1988, p. 160). A formação discursiva está sempre em referência às formações ideológicas.

Em nossos estudos temos analisado a formação discursiva do trabalho na sociedade capitalista. Como 
sabemos, nesse espaço de significação a marca da memória do discurso sobre o trabalho é a história dos conflitos de classe; esse é o real histórico atinente à memória discursiva. Nessa formação discursiva são articulados discursos diversos em forma de manuais de orientação para o trabalho nas empresas, de programas de gestão de pessoas ou de controle de qualidade, de propagandas e muitas outras formas discursivas.

Diante de enunciados - (1) É possível ter o máximo controle sobre os empregados, determinar normas rígidas, supervisionar, fiscalizar. Mas nada será tão eficaz quanto o espírito de colaboração e a iniciativa daqueles que acreditam no trabalho; ou (2) a empresa rompeu com os padrões tradicionais de trabalho (SEBRAE, 1994), que circulam no discurso de padrões e controle de qualidade dos serviços de uma empresa podem-se observar na superfície discursiva dizeres ocultados ou negados pelos sentidos predominantemente produzidos com as palavras em uso. Quando a palavra "rompeu" aparece no enunciado (2), aciona o sentido de "corte", de "ruptura", de "mudança". O discurso atual procura destituir o discurso de força caracterizado pelo poder das normas rígidas, do controle e da fiscalização, para enaltecer o da eficácia do espírito de colaboração, conforme se pode ver no enunciado (1). O velho discurso que sustentou os padrões tradicionais de trabalho é desmantelado pela força das evidências ideológicas, e, em seu lugar, é construído um discurso que se reveste de novos sentidos, com pose de "revolucionário".

No enunciado (2), a expressão "trabalho", embora tenha o mesmo referente na sociedade capitalista (é processo de produção de mercadoria que gera valor), parece ganhar novos sentidos. Perderia os sentidos de subordinação, de obediência, de desgaste e sofrimento, o que seria, segundo o discurso sugere, velhos padrões ou "padrões tradicionais"; ganharia os sentidos de liberdade, de colaboração, de autonomia, de alegria, "espírito de colaboração", de auto-afirmação, "iniciativa daqueles que acreditam no trabalho". Essas mudanças de sentido do 
trabalho se dariam através de um processo de mudanças de pensamento dos trabalhadores que passariam por uma nova formação de atitudes dentro da empresa. É o que veremos a seguir, quando discutirmos a proposta de educação que o discurso empresarial faz veicular no campo do trabalho, fazendo valer a máxima da matriz ideológica do capitalismo, almejando "educar" os indivíduos para se ajustar "sem dificuldades" à ordem burguesa.

\section{Sobre os efeitos de evidências ideológicas que mobilizam a educação para o trabalho}

Se for o destino da maioria dos homens viver dos frutos precários do trabalho, se o grande problema é melhorar a condição dos trabalhadores sem perturbar a ordem econômica, como presumem os pensadores da sociedade capitalista, é compreensível que a ideologia capitalista esteja voltada sobremaneira para a educação dos indivíduos visando ajustá-los à estrutura social consolidada pela sociedade burguesa. Nessa sociedade, o trabalho está sendo conduzido por um discurso que é válido, exatamente pela sua capacidade de obscurecer essa realidade, de desvirtuar a memória discursiva marcada pela luta de classes. O discurso sobre o trabalho encontra formas para operar na prática social, ganha marcas de programas, de administração e de gestão de pessoas para que se possa exercer o controle sobre o trabalho e os indivíduos se ajustem, "sem muitas dificuldades", às exigências do capitalismo.

Kaoru Ishikawa, ideólogo capitalista, consultor de empresas para assuntos de gerenciamento de pessoas, argumenta: "precisamos educar os trabalhadores. Precisamos fazê-los pensar e, em seguida, mudar seus padrões de pensamento." (ISHIKAWA, 1993, p.38-40). A educação de que trata o discurso não diz respeito à educação formal, a escolaridade do trabalhador, embora esse seja um tema atual e haja muitos encaminhamentos político-sociais para que os indivíduos se qualifiquem, aumentem o grau de escolaridade e possam competir no mercado com currículos mais avançados em graus de 
escolaridade. Muito menos diz respeito à educação que liberta o homem das garras do capital, que forma homens capazes de operar as mudanças necessárias para a construção de outra sociedade e de pensar e agir de forma a romper com a lógica do capital, conforme diz Mészáros (2005). Trata-se de uma "educação para o trabalho alienante, com o objetivo de manter o homem dominado" (idem, p. 12).

Nesse pressuposto, o sentido de educação é o que está corporificado na sociedade burguesa. Educar no discurso sobre o trabalho é uma prática que tem por objetivo "fornecer os conhecimentos e o pessoal necessário à maquinaria produtiva em expansão do sistema capitalista, mas também gerar e transmitir um quadro de valores que legitima os interesses dominantes" (MÉSZÁROS, 2005, p. 15). Educar, nesse discurso, implica preparar o pessoal para os procedimentos técnicos, significa adestrar o trabalhador, mudar seus valores, suas perspectivas de vida, e incorporar os padrões de consumo que deverão regular seu comportamento ante as exigências do capitalismo.

Quando uma empresa resolve mudar seus padrões de produção para se adequar ao sistema de competitividade no mercado, segue as recomendações e normas técnicas orientadas pelo capital, o sujeito invisível, universal, ideológico, que não tem corpo nem voz, mas "tudo pode naqueles que o fortalecem": os detentores dos meios de produção, os capitalistas. Estes tomam a forma de empresários e se fazem presentes através dos seus porta-vozes institucionais, como é o caso do sistema $\mathrm{S}$ no Brasil (Sesc, Senai, Sesi, Sebrae).

As instituições empresariais operam no sentido de introduzir na mente dos trabalhadores e dos empresários (também estes estão à mercê do capital) os valores de uma sociedade de mercado. Para Peter Druker (1996), outro idealizador dos meios eficazes para o fortalecimento do capitalismo, pretende-se mudar velhos paradigmas alicerces do capitalismo para novos valores que fundam uma sociedade pós-capitalista ou "sociedade do conhecimento", conforme defende em suas análises, 
alegando que, "no lugar do operário, está uma sociedade na qual o acesso a bons empregos não mais depende da carteira do sindicato, mas do diploma escolar." (idem, p. 220). Para esse autor, entretanto, a escola não transmite os conhecimentos necessários para os indivíduos adquirirem as habilidades requeridas pelos novos processos de trabalho, que, segundo ele, coloca a "pessoa no centro". A pessoa da sociedade do conhecimento seria a "pessoa instruída", “o símbolo", "o porta-bandeira da sociedade"; "ela define a capacidade de desempenho, mas também incorpora seus valores, crenças e compromissos" (DRUCKER, 1997, p. 166). Cabe à empresa investir em tecnologias modernas, processos de gestão de pessoas para contribuir com as mudanças que estão acontecendo e que as escolas ainda demorariam para promover em razão de uma formação atenta a novos paradigmas. Nessa linha de pensamento, os discursos dos padrões de controle de qualidade ganharam adeptos nos países capitalistas, tendo proliferado nas empresas durante o final do século $\mathrm{XX}$, na tentativa de mudar os hábitos dos empresários e dos trabalhadores.

Para esses discursos capitalistas, as mudanças de paradigma implicam mudança de pensamento, de valores, de cultura, de atitudes, de perspectivas. O discurso cria evidências ideológicas de que as mudanças trarão benefícios para todos. Recorre, entre muitas, a estratégias discursivas de apelo a fatores da subjetividade dos trabalhadores articulados em crendices populares, produzindo efeitos de mudanças nos costumes já arraigados culturalmente. É o caso das mudanças de paradigmas que justificaram muitas atitudes ao longo da história da humanidade. Foi o que identificamos em um determinado momento da nossa pesquisa; verificamos certos deslocamentos de sentidos no discurso dos padrões de controle do trabalho que, pelo seu poder popular, produzem os sentidos almejados pelo discurso da gestão e do controle do trabalho.

Quando todos acreditavam que "errar é humano" (Errar é humano), o sentido já sedimentado na memória 
${ }^{5}$ Uma análise mais detalhada desses enunciados foi feita no trabalho intitulado "O discurso do empresário: a re-significação das relaçōes de trabalho", apresentado na XV Jornada de Estudos Lingüísticos do Nordeste - Gelne, na Universidade Federal de Pernambuco, Recife, de 26 a 28 de novembro de 1997.

${ }^{6} \mathrm{O}$ homem é por natureza egoísta. "Essa seria uma inclinação geral do gênero humano, constituído por um perpétuo e irrequieto desejo de poder e mais poder que só termina com a morte". Para chegar ao poder, levado por suas paixões, o homem usaria diversos meios, inclusive a violência e a eliminação do seu próximo, o que tornaria a vida solitária, pobre, sórdida, embrutecida e curta. Assim, o estado natural (o homem egoísta) exige uma saída: o estabelecimento de regras e normas sociais para que o homem, ao segui-las, passe do seu estado natural para o estado social. Monteiro in Hobbes, $\mathrm{Os}$ pensadores (1997). discursiva é destituído e em seu lugar o discurso produz um novo sentido: "acertar é humano" (Acertar é humano). O mesmo fenômeno discursivo ocorre com outros enunciados: desacredita-se que "cachorro velho não aprende novos truques" (Cachorro velho não aprende novos truques) e leva-se a crer que "cachorro velho aprende novos truques" (Cachorro velho aprende novos truques); se "santo de casa não fazia milagre" (Santo de casa não faz milagre), agora "santo de casa faz milagres" (Santo de casa faz milagres); se, antes, na "casa de ferreiro o espeto era de pau" ( Casa de ferreiro, espeto de pau), agora o coerente é na "casa de ferreiro ter espeto de ferro" (Casa de ferreiro, espeto de ferro ) ${ }^{5}$.

Todos esses ditados populares de natureza negativista estão apoiados em paradigmas filosóficos que representam o homem como naturalmente limitado pelas suas ambições ${ }^{6}$ - um estado natureza que caracteriza o homem antes de entrar no estado social. Segundo esse preceito, todos os homens são naturalmente iguais, suas fraquezas ou sua força advêm desse estado natureza; é o estado pré-social do homem. Para controlar e ultrapassar essa condição natural do ser humano, para que o homem se constitua um ser social, instituem-se as normas de comportamento. Todos passam a obedecer a um conjunto de leis que regulam a conduta em sociedade. Explicita-se a relação entre comandados, os que devemfazer, e comandantes, os que podem-saber, e todo o processo de produção e de relações sociais passa a ser regido por essa máxima?.

As mudanças de paradigma propostas pelo discurso do controle do trabalho instauram um processo de simulação de evidências de mudanças e resignificação ${ }^{8}$ dos valores sedimentados na historia da sociedade capitalista e das formações ideológicas que sustentam as relações de trabalho nesta sociedade. Ao se apropriar dos ditados populares para argumentar a favor dos princípios dos novos paradigmas que o discurso sugere, modificando o pensamento e a conduta dos trabalhadores, a ideologia enaltece a individualidade com 
todos os predicados da subjetividade que revigoram a máxima de que "querer é poder". É com essa estratégia discursiva que o discurso procura quebrar a resistência às mudanças no mundo do trabalho.

\section{Conclusão}

Enfim, para que os trabalhadores precisam ser educados? Para ser adestrados em função das exigências do capitalismo, para ser adaptados às novas formas de exploração da sua força de trabalho, formas mais disfarçadas, revestidas do caráter sofisticado que a nomenclatura "sociedade do conhecimento" ou "sociedade pós-capitalista" produz.

Nesse espaço discursivo do trabalho, a ideologia produz evidências de que a educação do trabalhador é a chave que este teria para conquistar a liberdade, para mudar a sua condição de dependência e subordinação no trabalho. Mas essa condição de libertação é impossível nas condições efetivas da sociedade capitalista, pois o capital não tem limites para sua expansão, e qualquer tentativa de superar a realidade do metabolismo social do capital através das intenções, do pensamento e da "educação" está fadada à derrota (MÉSZÁROS, 2005). Sobre as tentativas dos homens em transformar a realidade por meio da "educação", Marx (1986, p. 12) previne, ao pôr em discussão a filosofia materialista de Feuerbach :

A doutrina materialista, segundo a qual os homens são produtos das circunstâncias e da educação e, portanto, segundo a qual os homens transformados são produtos de outras circunstâncias e de uma educação modificada, esquece que são precisamente os homens que transformam as circunstâncias e que o próprio educador deve ser educado. Por isso, essa doutrina chega, necessariamente, a dividir a sociedade em duas partes, uma das quais é colocada acima da sociedade.

A coincidência da modificação das circunstâncias com a atividade humana ou alteração de si próprio
${ }^{7}$ Lembramos aqui o processo de produção industrial com base no taylorismo e no fordismo, que faz bem essa distinção entre os que pensam e os que executam. Caberia aos administradores e engenheiros formular padrões de normatização da produção e das relações de trabalho. Caberia aos operários obedecer às normas e efetivar a produção.

${ }^{8}$ A noção de resignificação está articulada com a noção de interdiscursividade, um processo inerente à constituição do discurso, "um trabalho sobre outros discursos". Aponta, também, para a noção de discurso fundador que é explicitada por ZoppiFontana (1993) e Orlandi (1993). O discurso fundador "cria uma nova tradição, ele re-significa o que veio antes e institui aí uma memória outra.[...]. Instala-se outra tradição de sentidos que produz outros sentidos nesse lugar. [...] ele sustenta o sentido que surge e se sustenta nele. Intervém no já dado, no já dito" (ORLANDI, 1993, p.13). 
A essa forma de ser do discurso fundador está dada a possibilidade de estabelecer mudanças fundamentais no modo de ser dos sujeitos que vão se constituindo historicamente.

Absorvidos pelos efeitos dos processos discursivos já instalados, os sujeitos, nessa relação, vão também instalando novos sentidos ao que está dito, instituindo novos discursos que, embora pareçam novos, trazem o velho na sua estrutura, provocando "um todo com determinante", interdiscursivamente. só pode ser apreendida e compreendida racionalmente como práxis revolucionária.

No discurso dos novos padrões de controle de qualidade dentro das empresas produzem-se evidências de emancipação do homem de seu fatídico destino por meio da mudança do pensamento, da educação, e assim instala-se um "mundo" cheio de esperanças para o trabalhador. Nesse discurso, a ideologia do capitalismo alimenta um novo "sonho", assim como nas promessas iluministas; cria ilusões de uma vida melhor, mais segura, mais saudável. Vê-se, pois, que os sentidos produzidos no discurso são efeitos da ideologia; é a ideologia dominante da sociedade capitalista produzindo evidências, certezas aparentemente inquestionáveis, através do discurso empresarial. O discurso do capitalismo que focaliza o trabalho como seu tema central apaga a educação a que todos têm direito, educação no sentido da formação do homem para sua libertação. Ser livre e mandar no seu próprio destino é a finalidade maior que mobilizaria os homens, mas que só seria possível se o domínio do capital e se sua natureza destrutiva fossem completamente aniquilados, ação "apreendida e compreendida racionalmente como práxis revolucionária”

Porém, como disse Chico Buarque: 


\section{Referências}

AMARAL, M. Virgínia Borges. Discurso e relações de trabalho. Maceió:Edufal, 2005.

- O avesso do discurso: análise de práticas discursivas no campo do trabalho. Maceió: Edufal, 2007.

DRUCKER, Peter. Administrando para o futuro: os anos 90 e a virada do século. São Paulo: Pioneira, 1996.

. Sociedade pós-capitalista. São Paulo: Pioneira, 1996.

ISHIKAWA, Kaoru. Controle de qualidade total à maneira japonesa. Rio de Janeiro, Campus, 1993.

LUKÁCS, G. O problema da ideologia. Trad. de Ester Vaisman. João Pessoa, mimeo, 1986.

MARX, K. e ENGELS, F. A ideologia alemã. São Paulo: Hucitec, 1986.

MARX, K. A questão judaica. São Paulo: Moraes, 1988.

. Contribuição à crítica da economia política. São Paulo:

Martins Fontes, 1983.

MÉSZÁROS, Istvan. Produção destrutiva e Estado capitalista.

São Paulo: Ensaio, 1989.

. O poder de ideologia. São Paulo: Boitempo, 2004.

. A educação para além do capital. São Paulo: Boitempo,

2005.

ORLANDI, Eni Puccinelli. Discurso fundador: a formação do

país e a construção da identidade nacional. São Paulo: Pontes,

1993.

PÊCHEUX, Michel. Semântica e discurso: uma crítica à

afirmação do óbvio. Campinas: Editora da Unicamp, 1988.

SEBRAE/FOLHA DE S.PAULO. Qualidade Total. São Paulo, 1994.

VAISMAN, Ester. A ideologia e sua determinação ontológica.

In: Ensaio. São Paulo: Ensaio, no 17-18, 1989, p. 399-444 .

ZOPPI-FONTANA, Mónica G. Sonhando a pátria: os

fundamentos de repetidas fundações. In: ORLANDI, Eni (Org.).

Discurso fundador. São Paulo: Pontes, 1993. 